\title{
Effect of microencapsulated sodium butyrate in the close-up diet on performance of dairy cows in the early lactation period
}

\author{
Z. M. Kowalski, ${ }^{* 1}$ P. Górka, ${ }^{*}$ J. Flaga, ${ }^{*}$ A. Barteczko, ${ }^{*}$ K. Burakowska, ${ }^{*}$ J. Oprządek, $†$ and R. Zabielskił \\ *Department of Animal Nutrition and Feed Management, University of Agriculture in Krakow, Al. Mickiewicza 24/28, 30-059 Krakow, Poland \\ †Department of Animal Improvement, Institute of Genetics and Animal Breeding Polish Academy of Sciences, UI. Postępu 36A, \\ 05-552 Magdalenka, Poland \\ $\ddagger$ Department of Physiological Sciences, Faculty of Veterinary Medicine, Warsaw University of Life Sciences, Ul. Nowoursynowska 159, \\ 02-766 Warszawa, Poland
}

\begin{abstract}
Two trials were conducted to determine the effect of sodium butyrate microencapsulated within triglyceride matrix (Na-butyrate) in the close-up period on performance of dairy cows and rumen papillae development. In trial 1, 26 Holstein-Friesian cows were randomly allocated to 2 groups (13 cows/group) and fed prepartum a total mixed ration (TMR) without or with $300 \mathrm{~g}$ of Na-butyrate/d from $30 \mathrm{~d}$ before expecting calving to parturition. After calving, the same lactational TMR without Na-butyrate was offered to both treatments. Dry matter intake and milk yield were monitored daily to $60 \mathrm{~d}$ in milk, and body condition of cows was scored on d 30, 21, and 4 before parturition and d 14, 31, and 60 after parturition. On d 15, 10, and 5 before parturition blood samples were collected from 6 cows randomly chosen from each group and analyzed for plasma $\beta$-hydroxybutyrate and nonesterified fatty acids concentrations. No differences in dry matter (DM) intake, milk yield, body condition score, or plasma $\beta$-hydroxybutyrate and nonesterified fatty acids concentrations was observed between treatments; however, in the last $5 \mathrm{~d}$ before parturition the cows receiving Na-butyrate ate $1.7 \mathrm{~kg}$ of $\mathrm{DM} / \mathrm{d}$ more, on average, as compared with control cows. In trial 2, 12 HolsteinFriesian growing bulls ( $404 \pm 48$; body weight \pm SD) were used to determine the effect of Na-butyrate inclusion in the diet on rumen papillae development. Bulls were randomly allocated to 2 groups (6 bulls/group) and fed TMR without or with $2 \%$ (on a dry matter basis) of Na-butyrate for $21 \mathrm{~d}$. At the end of the study, bulls were killed and rumen fluid and rumen tissue samples from dorsal and ventral sac of the rumen were collected. No effect of Na-butyrate supplementation on BW of bulls and DMI during the trial period was observed. Sodium butyrate supplementation increased
\end{abstract}

Received July 31, 2014.

Accepted January 18, 2015.

${ }^{1}$ Corresponding author: rzkowals@cyf-kr.edu.pl total short-chain fatty acid concentration in the rumen but had no effect on rumen $\mathrm{pH}$, molar proportions of short-chain fatty acids, and $\mathrm{NH}_{3}-\mathrm{N}$ concentration. In dorsal sac of the rumen, papillae length and papillae cross-section surface area were increased as a result of Na-butyrate supplementation, whereas in the ventral sac a reverse effect was observed (significant treatment $x$ location in the rumen interaction). Both in the dorsal and ventral sac of the rumen, dietary Na-butyrate increased rumen muscle layer thickness. Altogether, results of this study suggest that Na-butyrate supplementation in the close-up diet may have a potential to enhance rumen papillae growth and rumen adaptation to postpartum diet but lactation performance were not affected under conditions of the current study.

Key words: transition period, dry matter intake, rumen papillae

\section{INTRODUCTION}

Dry matter intake in first weeks of lactation does not cover nutritional needs of high-yielding dairy cows. As a result, cows undergo negative energy balance, which is a main cause of metabolic disorders and poor fertility (Ingvartsen, 2006; Grummer et al., 2010).

An important factor that determines DMI after parturition, and thus severity of negative energy balance, is rumen adaptation to the postpartum diet. Concentrate feeding initiated 2 to 3 wk before expected parturition is a commonly used strategy to enhance rumen adaptation and increase the efficiency to use diets rich in starch postpartum (Grummer et al., 2010). Besides assuring adequate rumen microflora adaptation, such a feeding strategy stimulates rumen papillae growth, and thus increases surface area of nutrients absorption postpartum (Bannink et al., 2008). However, even 50\% of the absorptive area in the rumen may be lost during a common 6- to 8-wk of period when a low-starch diet is provided prepartum; the same amount of time may be required to restore this loss (Dirksen et al., 1984). Although this process may be faster when the prepartum 
diet contains sources of starch easily fermented in the rumen (such as barley; Reynolds et al., 2004), or even very fast when a high-starch diet is offered (Bannink et al., 2008), such a close-up diet may lead to energy overconsumption, which in turn may negatively affect performance of cows after calving (Beever, 2006; Loor et al., 2006). Moreover, the high-starch diets are often related to the risk of rumen acidosis (Penner et al., 2009). Therefore, moderate- or even low-starch closeup diets are currently recommended in some models of dairy cows nutrition (Beever, 2006; Loor et al., 2006); however, this may not necessarily sustain adequate stimulation for the rumen papillae growth. Conversely, due to a high probability of overconditioning of cows, concentrate feeding should not be initiated earlier than 3 to 4 wk before expected parturition (Grummer, 2007). As a result, commonly practiced feeding systems of close-up cows may not sustain adequate rumen epithelium preparation, namely rumen papillae length and width, for efficient nutrients absorption after parturition.

It is well documented that butyric acid and, to a lesser extent, propionic acid are the main stimulators of rumen epithelial cells proliferation and papillae growth (Mentschel et al., 2001; Malhi et al., 2013). Our previous study showed that sodium butyrate microencapsulated within triglyceride matrix (Na-butyrate) supplementation in starter mixture, at amounts equal to $0.3 \%$ ( $0.09 \%$ of sodium butyrate; as fed), stimulated rumen papillae development and solid feed intake in newborn calves (Górka et al., 2011). Furthermore, DeFrain et al. (2006) showed that lactose feeding to increase butyric acid production in the rumen reduced the DMI drop before parturition. If promotion of butyric acid production in the rumen stimulates papillae growth and DMI, a direct addition of butyric acid or its sodium salt to the TMR in the close-up period could have a favorable effect on DMI, both before and after calving. However, the amount of dietary butyric acid delivery should ensure its positive effect on rumen mucosa, but without increasing the BHBA content in the blood above the level typical for subclinical ketosis (e.g., 1.0 to $1.4 \mathrm{mmol} / \mathrm{L}$; Duffield et al., 1998).

We hypothesized that supplementation of close-up diets with Na-butyrate would increase papillae dimensions and would positively affect DMI, both before and after calving, and performance of cows. To verify this hypothesis, 2 trials were conducted. Trial 1 aimed to determine whether Na-butyrate supplementation prepartum affects DMI and milk yield in high-yielding dairy cows. In turn, trial 2 aimed to determine whether dietary Na-butyrate supplementation in fact affects rumen papillae dimensions.

\section{MATERIALS AND METHODS}

The animal study protocols were approved by the local ethics committee in Krakow, Poland, before the onset of the trials. Trial 1 was conducted at the Research and Extension Unit of Breeding State Farm Osięciny (Poland), whereas trial 2 was conducted at the Research Unit of the Institute of Genetics and Animal Breeding Polish Academy of Sciences (Jastrzębiec, Poland).

\section{Trial 1}

Twenty-six multiparous Holstein-Friesian cows at 30 $\mathrm{d}$ before expected calving were randomly allocated to 2 groups (13 cows/group) and fed a close-up TMR without (control) or with $300 \mathrm{~g}$ of microencapsulated Nabutyrate/d (Na-B). Microencapsulated Na-butyrate (Vetagro, Reggio Emilia, Italy) contained $30 \%$ of sodium butyrate and $70 \%$ of triglyceride matrix. This resulted in sodium butyrate intake equal to $90 \mathrm{~g} / \mathrm{d}(71.1 \mathrm{~g} / \mathrm{d}$ of butyrate) for Na-B. After calving, the same lactational TMR without Na-butyrate was offered to both treatments, and DMI and milk yield were recorded daily until 60 DIM. Cows were housed in a freestall barn with rubber mats covering floor and fed individually using Calan gates system (American Calan, Northwood, NH) once daily at $1000 \mathrm{~h}$. The amount of TMR offered was adjusted daily to ensure $10 \%$ refusals. Representative samples of prepartum and postpartum TMR diets were collected weekly and kept frozen $\left(-20^{\circ} \mathrm{C}\right)$ until further analysis. Sodium butyrate was offered to the cows before TMR allocation, after mixing with $1 \mathrm{~kg}$ of concentrate, to ensure its entire intake. Sodium butyrate microencapsulated within triglyceride matrix (Vetagro; 30:70 butyrate-to-triglyceride matrix) was used to slow down the butyric acid release in the rumen (predicted time of release $16 \mathrm{~h}$ ). On d 30, 21, and 4 before parturition and d 14, 31, and 60 after parturition, BCS was assessed. On d 15 (actual d $16.2 \pm 1.8), 10(11.7 \pm 1.8)$, and $5(6.2 \pm 1.8)$ before expected parturition, blood samples from the jugular vein were collected from 6 cows randomly chosen from each group into heparincoated tubes (16 IU/mL of blood; Sarstedt, Nümbrecht, Germany). The tubes were immediately put on ice, cooled, and centrifuged at $2,300 \times g$ for $10 \mathrm{~min}$ at $4^{\circ} \mathrm{C}$. Blood plasma was frozen and stored at $-20^{\circ} \mathrm{C}$ until analyzed for BHBA and NEFA concentrations.

Samples of TMR were analyzed for DM, ash, CP, crude fat, and crude fiber were determined using standard analytical procedures (method nos. 934.01, 942.05, 976.05, 2003.05, 962.09 for DM, ash, CP, and crude fiber, respectively; AOAC International, 2007). Both NDF and ADF were determined according to 
Goering and Van Soest (1970) using Ankom220 Fiber Analyzer (Ankom Technology Corporation, Fairport, NY). Starch content was determined by the enzymatic method of Faisant et al. (1995). Body condition of cows was scored by 2 experienced persons according to Edmonson et al. (1989), using a 5-point scale and 0.25 increments. Plasma BHBA was determined on automatic chemical analyzer (Hitachi 902; Hitachi, Tokyo, Japan) using Diagnostic Systems Laboratories (Sinsheim, Germany) reagents. Plasma NEFA concentration was determined on a spectrophotometer (Epoll 20; Poll Ltd., Warszawa, Poland) using Wako Chemicals GmbH reagents (Neuss, Germany). For feeds evaluation, the INRA (2007) system was used.

Due to the health problems not related with the study, 2 cows from the control group were excluded from trial 1; thus, data from 11 and 13 cows were analyzed for control and Na-B, respectively. Prepartum and postpartum data were analyzed separately. Data on milk yield and DMI were reduced to 5-d means and then analyzed. Statistical analysis was performed using the PROC MIXED procedure of SAS (2002). Repeated measurements on one animal were analyzed as repeated measures. The statistical model for repeated variables included cow as a random effect, experimental group (control or Na-B), time (d or 5-d mean), and interaction between group and time as fixed effects (Littell et al., 1998). Optimal covariance structure was chosen based on Akaike's criterion. For data not repeated in time the statistical model with fixed effect of experimental group and random effect of cow was used. The significance was declared at $P \leq 0.05$ and tendencies at $P \leq 0.10$. Data are presented as least squares means and corresponding SEM.

\section{Trial 2}

In trial 2, 12 Holstein-Friesian growing bulls were used to verify whether Na-butyrate inclusion in the diet affected rumen epithelium structure. At the initiation of a trial the bulls $(404 \pm 48$; BW $\pm \mathrm{SD})$ were randomly allocated to 2 groups (6 bulls/group) and fed a TMR without (control) or with $2 \%$ (on DM basis) of microencapsulated Na-butyrate (Vetagro; 30:70 butyrate-to-triglyceride matrix, predicted time of release 16 h; Na-B). Microencapsulated Na-butyrate used in trial 2 was the same product as that used in trial 1, but TMR compositions differed between those 2 studies. Bulls were fed individually using a Calan gates system (American Calan) once daily at $0800 \mathrm{~h}$. The amount of TMR offered was adjusted daily to ensure $10 \%$ refusals. Representative samples of TMR were collected weekly and kept frozen $\left(-20^{\circ} \mathrm{C}\right)$ until further analysis.
Experimental diets were fed for $21 \mathrm{~d}$. At the end of the study bulls were killed after a 24-h fast. Right after slaughter the stomach was dissected, reticulorumen opened, and representative samples of rumen fluid were collected. Whole-thickness rumen wall samples were collected from ventral and dorsal sac of the rumen and rinsed in PBS (Sigma-Aldrich, St. Louis, MO) until clean. Because only 2 animals were killed at one time, tissue samples were kept in PBS, transported to the laboratory, and within several hours used for papillae length and width and muscle layer thickness measurements. All bulls were slaughtered at the age of 15 mo.

Samples of TMR were analyzed and nutritive value of feeds was evaluated using the same procedures as described for trial 1. Magnification glass (Olympus, Tokyo, Japan) and computer software (AxioVision Rel. 4.7; Zeiss, Oberkochen, Germany) were used for morphometric measurements of rumen papillae height, width, cross-section area (height $\times$ width), and muscle layer thickness. At least 4 pictures were taken for each tissue sample and all papillae visible on each picture (10 in most cases) were measured. A mean for all papillae and animal was used for statistical evaluation.

Due to incomplete data on feed intake for 1 bull from the control group, data from 5 and 6 animals from the control and Na-B groups, respectively, were subjected to statistical analysis. Data were analyzed using PROC MIXED statement of SAS (2002). The statistical model included group (control or Na-B) and rumen sac (dorsal or ventral) and interaction between those effects (for rumen epithelium parameters analysis) as a fixed effect. Significance was declared at $P \leq 0.05$ and tendencies at $P \leq 0.10$. Data are presented as least squares means and corresponding SEM.

\section{RESULTS}

\section{Trial 1}

Ingredient and chemical composition of prepartum and postpartum TMR diets are in Table 1. Actual number of days on treatment prepartum equaled 30.1 $( \pm 2.8)$ and $30.3( \pm 2.1)$ for control and Na-B, respectively, and did not differ between treatments $(P>0.05$; Table 2). No difference between treatments in DMI in the close-up period was observed. However, in the last 5 d before parturition the cows from Na-B group ate on average $1.7 \mathrm{~kg}$ of $\mathrm{DM} / \mathrm{d}$ more as compared with control cows (Table 2 and Figure 1). There was no effect of dietary Na-butyrate supplementation on postpartum DMI, milk yield, BCS (both before and after parturition), and prepartum plasma NEFA and BHBA concentrations $(P>0.05)$. 
Table 1. Ingredient and chemical composition of experimental diets

\begin{tabular}{|c|c|c|c|}
\hline \multirow[b]{2}{*}{ Item } & \multicolumn{2}{|c|}{ Trial $1^{1}$} & \multirow[b]{2}{*}{ Trial 2} \\
\hline & Prepartum & Postpartum & \\
\hline \multicolumn{4}{|l|}{ Ingredient, \% of DM } \\
\hline Corn silage & 36.0 & 28.7 & 55.3 \\
\hline Alfalfa haylage & 20.1 & 18.8 & \\
\hline Corn-cob mix & & 16.2 & \\
\hline Corn grain & 5.5 & & \\
\hline Soybean meal & & 15.5 & \\
\hline Dry beet pulp & & 3.8 & \\
\hline Molasses & & 6.0 & \\
\hline Straw & 7.8 & 3.5 & \\
\hline Gras hay & & & 8.9 \\
\hline Concentrate + mineral vitamin supplement & 30.6 & 7.4 & 35.8 \\
\hline \multicolumn{4}{|l|}{ Chemical composition } \\
\hline DM, \% & 47.5 & 46.7 & 47.6 \\
\hline $\mathrm{CP}, \%$ of $\mathrm{DM}$ & 14.5 & 17.2 & 13.3 \\
\hline Crude fiber, $\%$ of DM & 21.5 & 14.4 & 21.6 \\
\hline Starch, \% of DM & 17.8 & 29.4 & 19.6 \\
\hline NDF, $\%$ of DM & 41.2 & 30.0 & 42.6 \\
\hline $\mathrm{ADF}, \%$ of $\mathrm{DM}$ & 27.8 & 19.3 & 29.2 \\
\hline Ash, $\%$ of DM & 9.1 & 5.8 & 9.0 \\
\hline $\mathrm{UFL},{ }^{3}$ unit $/ \mathrm{kg}$ of $\mathrm{DM}$ & 0.81 & 0.93 & \\
\hline $\mathrm{UFV}^{3}{ }^{3}$ unit $/ \mathrm{kg}$ of $\mathrm{DM}$ & & & 0.84 \\
\hline $\mathrm{PDIN}^{3} \mathrm{~g} / \mathrm{kg}$ of DM & 88 & 93 & 82 \\
\hline $\mathrm{PDIE}^{3} \mathrm{~g} / \mathrm{kg}$ of DM & 80 & 89 & 78 \\
\hline $\mathrm{LFU}^{3}$ unit/kg of DM & 1.04 & 1.01 & \\
\hline $\mathrm{CFU}^{3}{ }^{3}$ unit/kg of DM & & & 0.99 \\
\hline
\end{tabular}

${ }^{1}$ Prepartum diet for the Na-butyrate group was supplemented with $300 \mathrm{~g} / \mathrm{d}$ of microencapsulated within triglyceride matrix sodium butyrate.

${ }^{2}$ Diet for Na-butyrate group contained $2 \%$ of microencapsulated within triglyceride matrix sodium butyrate, which was achieved by replacing an equal portion of corn silage.

${ }^{3}$ Calculated from INRA 2007: UFL $=$ feed unit for lactation; UFV $=$ feed unit for maintenance and meat production; PDIN = protein digestible in intestine counted on $\mathrm{N}$ in rumen; PDIE = protein digestible in intestine counted on energy in rumen; $\mathrm{LFU}=$ fill unit for lactation; $\mathrm{CFU}=$ fill unit for cattle.

\section{Trial 2}

Ingredient and chemical composition of experimental diet are in Table 1. Initial BW, final BW, and DMI, both absolute and expressed as a percentage of BW, were not different between treatments $(P>0.05$; Table 3). Total rumen short-chain FA (SCFA) was higher for Na-B $(P=0.04)$ compared with control, with no differences observed for other rumen fermentation parameters.

There was a sampling place (dorsal vs. ventral sac) $\times$ treatment interaction observed for rumen papillae length and surface area $(P \leq 0.05$; Figure 2$)$. In the dorsal sac of the rumen, the papillae length and papillae surface area were the highest for the Na-B group, whereas in the ventral sac a reverse effect was found. Both in the dorsal and ventral sac of the rumen $\mathrm{Na}$ butyrate increased rumen muscle layer thickness $(P=$ $0.01)$.

\section{DISCUSSION}

The stimulatory effect of butyric acid on rumen epithelium growth and function is well established.
Butyric acid stimulates proliferation, concomitantly reducing the amount of cells undergoing apoptosis, which results in rumen papillae growth and enlargement of surface area for nutrient absorption (Mentschel et al., 2001; Guilloteau et al., 2010; Malhi et al., 2013). Furthermore, a positive effect of increasing butyric acid concentration in the rumen on some proteins mediating SCFA absorption across the rumen epithelium was shown (Kuzinski and Rontgen, 2011; Laarman et al., 2012; Dengler et al., 2014). Our previous study showed that dietary Na-butyrate supplementation, used as a source of butyric acid, had a favorable effect on rumen epithelium growth and feed intake in calves (Górka et al., 2011). In the current study, an attempt to use dietary Na-butyrate to simulate rumen papillae growth and DMI in the close-up period for dairy cows was made. Because dry cows are usually fed diets high in fiber (and thus low in starch and other unstructured carbohydrates), which results in low butyric acid production in the rumen (and also contributes to high abrasive properties of the diet), rumen papillae dimensions may be substantially reduced during the commonly practiced dry period (Dirksen et al., 1984; 


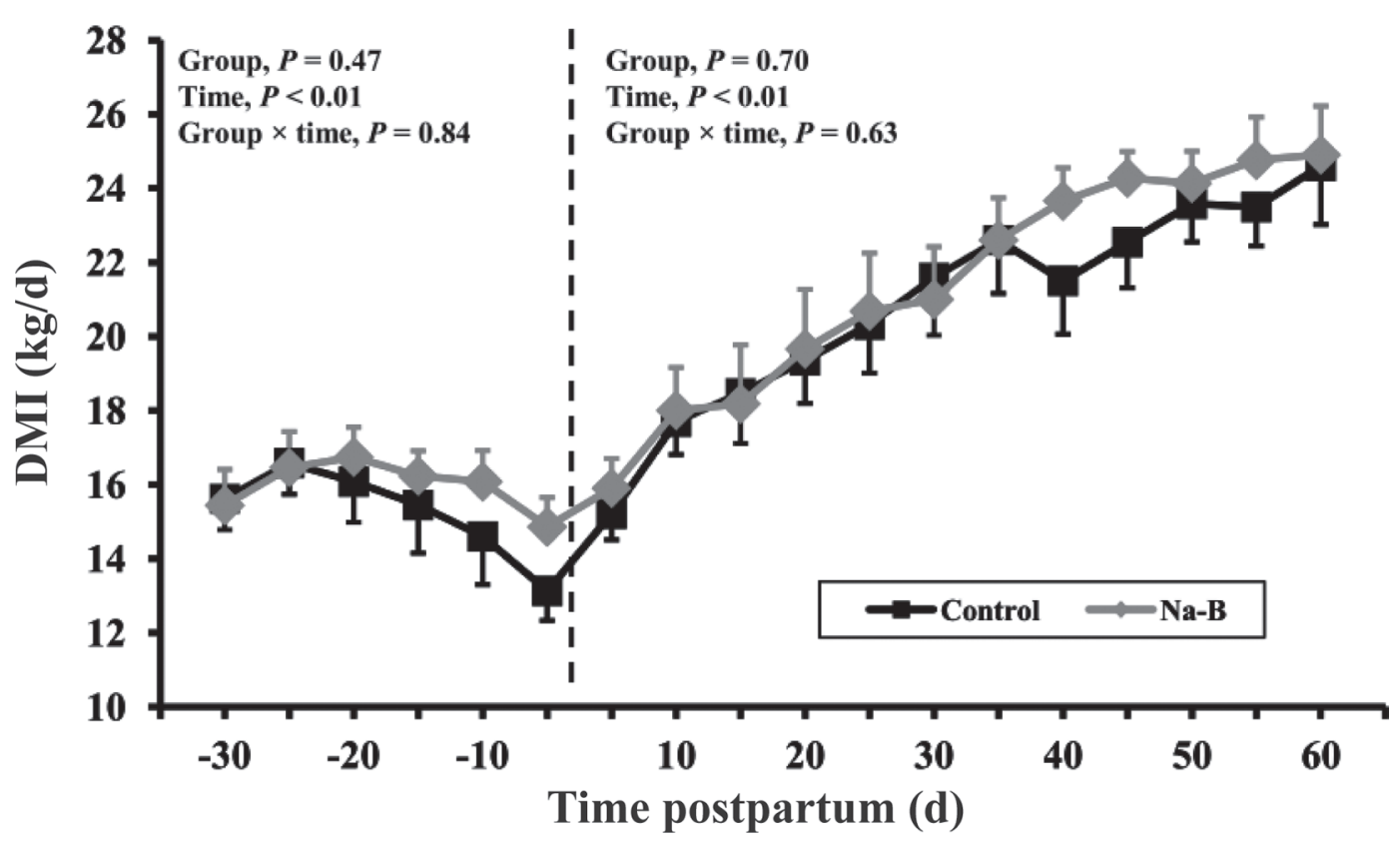

Figure 1. Least squares means and corresponding SE for DMI by Holstein-Friesian cows in trial 1. Each point on the graph represents a mean for 11 and 13 observations for the control (no supplemental microencapsulated sodium butyrate) and Na-B (2\% of microencapsulated sodium butyrate in DM) groups, respectively.

Bannink et al., 2008). This, in turn, may negatively affect the cow's transition to lactation due to inadequate rumen epithelium adaptation to high in concentrate postpartum diet (Grummer, 2007).

Although no effect of Na-butyrate supplementation on DMI pre- and postpartum was shown in the present study, a lower DMI drop before calving was observed for cows offered Na-butyrate (Figure 1). This corresponds with the results of DeFrain at al. (2006), who showed a lower DMI depression $1 \mathrm{wk}$ before calving in response to lactose inclusion in the diet and increased butyric acid concentration in the rumen. Furthermore, Na-

Table 2. Least squares means for DMI, milk yield, BCS, and plasma BHBA and NEFA concentrations in trial 1

\begin{tabular}{|c|c|c|c|c|}
\hline \multirow[b]{2}{*}{ Item } & \multicolumn{2}{|c|}{ Group $^{1}$} & \multirow[b]{2}{*}{ SEM } & \multirow[b]{2}{*}{$P$-value ${ }^{2}$} \\
\hline & Control & $\mathrm{Na}-\mathrm{B}$ & & \\
\hline Number of cows & 11 & 13 & & \\
\hline \multicolumn{5}{|l|}{ Prepartum } \\
\hline Days on treatment & 30.1 & 30.3 & 0.47 & 0.80 \\
\hline $\mathrm{DMI},{ }^{3} \mathrm{~kg} / \mathrm{d}$ & 15.2 & 16.0 & 0.27 & 0.47 \\
\hline $\mathrm{BCS}$ & 3.15 & 3.13 & 0.01 & 0.57 \\
\hline Butyrate intake, $\mathrm{g} / \mathrm{d}$ & - & 71.1 & - & - \\
\hline \multicolumn{5}{|l|}{ Plasma concentration ${ }^{4}$} \\
\hline $\mathrm{BHBA}, \mathrm{mmol} / \mathrm{L}$ & 0.39 & 0.38 & 0.02 & 0.73 \\
\hline NEFA, mmol/L & 0.19 & 0.26 & 0.04 & 0.16 \\
\hline \multicolumn{5}{|l|}{ Postpartum } \\
\hline $\mathrm{DMI},{ }^{3} \mathrm{~kg} / \mathrm{d}$ & 20.9 & 21.5 & 0.30 & 0.70 \\
\hline $\mathrm{BCS}^{2}$ & 2.96 & 2.97 & 0.02 & 0.69 \\
\hline BCS change ${ }^{5}$ & 0.18 & 0.15 & 0.02 & 0.53 \\
\hline Milk yield, ${ }^{3} \mathrm{~kg} / \mathrm{d}$ & 44.4 & 44.7 & 0.54 & 0.86 \\
\hline
\end{tabular}

${ }^{1}$ Control = no supplemental microencapsulated sodium butyrate; Na-B $=300 \mathrm{~g}$ of microencapsulated sodium butyrate/d.

${ }^{2}$ Effect of group in the model $(P<0.01)$.

${ }^{3}$ Significant effect of time in the model $(P<0.01)$.

${ }^{4} \mathrm{n}=6$ /treatment.

${ }^{5}$ Day 4 prepartum compared with d 31 postpartum. 
Table 3. Least squares means for BW of bulls, DMI, and rumen fermentation parameters in trial 2

\begin{tabular}{lcccc}
\hline & \multicolumn{2}{c}{ Group $^{1}$} & & \\
\cline { 2 - 3 } Item & Control & Na-B & SEM & $P$-value \\
\hline Number of bulls & 5 & 6 & & \\
BW, kg & 379 & 425 & 14.4 & 0.11 \\
Initial & 405 & 453 & 15.7 & 0.13 \\
Final & 9.02 & 9.64 & 0.50 & 0.57 \\
DMI, kg/d & 2.30 & 2.17 & 0.07 & 0.44 \\
DMI, \% of BW & - & 45.7 & & - \\
Butyrate intake, g/d & 7.19 & 7.00 & 0.06 & 0.17 \\
Rumen pH & 61.2 & 81.4 & 5.18 & 0.04 \\
Rumen short-chain FA, mM & 67.1 & 69.6 & 1.03 & 0.24 \\
Acetate, \% & 20.2 & 17.2 & 1.12 & 0.20 \\
Propionate, \% & 9.3 & 10.2 & 0.75 & 0.58 \\
Butyrate, \% & 1.18 & 0.95 & 0.08 & 0.17 \\
Valerate, \% & 0.95 & 0.72 & 0.06 & 0.24 \\
Isobutyrate, \% & 1.30 & 1.30 & 0.15 & 0.98 \\
Isovalerate, \% & 3.51 & 4.09 & 0.24 & 0.25 \\
Acetate:propionate & 0.73 & 0.78 & 0.07 & 0.77 \\
Rumen N-NH , mg\% & & & & \\
\hline${ }^{1}$ Control = no supplemental microencapsulated sodium butyrate; & Na-B $=2 \%$ of microencapsulated sodium \\
butyrate in DM. & & &
\end{tabular}

butyrate supplementation in the diet for growing bulls (trial 2) increased SCFA concentration in the rumen and affected rumen papillae dimensions, suggesting a positive effect on rumen fermentation and rumen epithelium structure. Because DMI was not affected when Na-butyrate was included in the diet for bulls, higher SCFA concentration in the rumen of those animals should be referred to more intense (and probably more efficient) microbial fermentation of nutrients. Butyric acid infusion into the rumen was shown to increase total-tract digestibility of $\mathrm{OM}$ in lactating dairy cows, including digestibility of NDF, a nutrient digested predominantly in the forestomach (Huhtanen et al., 1993). Furthermore, butyric acid infusion into the rumen of dairy cows had substantial effect on rumen microflora composition ( $\mathrm{Li}$ et al., 2012).

Due to digesta stratification in the rumen, the most intense microbial fermentation occurs in the dorsal and central part of the rumen (Aschenbach et al., 2011). As such, if Na-butyrate stimulated nutrient digestion, this took place to a higher extent in the dorsal region of the rumen, which may explain higher rumen papillae in this rumen location for the Na-B group. However, it cannot be excluded that Na-butyrate was entrapped within digesta particles floating in the rumen, and thus butyrate was released from microcapsules predominantly in the dorsal sac, resulting in stimulation of rumen epithelial cell proliferation mainly in this region of the rumen. A shift in the intensity of nutrient digestion to the dorsal sac of the rumen may also explain lower rumen papillae in the ventral sac.

In the current study, supplemental butyrate intake amounted to $71.1 \mathrm{~g} / \mathrm{d}$ in trial 1 and $45.7 \mathrm{~g} / \mathrm{d}$ in trial
2. This accounted for 0.44 to $0.47 \%$ of DM consumed by the animals. In previous studies that showed a substantial effect of butyric acid on rumen papillae growth and rumen epithelium function, much higher doses of butyric acid were offered in the diet or infused directly into the rumen, ranging from 1.5 to over $6 \%$ of $\mathrm{DM}$ offered to animals (Shen et al., 2005; Malhi et al., 2013; Wiese et al., 2013). Such large doses of butyric acid could allow for doubling or even tripling its estimated production in the rumen (Bergman, 1990). However, $0.09 \%$ of supplemental butyrate in solid feed $(0.3 \%$ of microencapsulated sodium butyrate product) was sufficient for stimulation of rumen epithelium development in newborn calves (Górka et al., 2011). Even the lowest doses of butyric acid used in the study of Huhtanen et al. (1993) and Wiese et al. (2013), which amounted to $1.5 \%$ of DM, had a pronounced effect on rumen epithelium function in sheep and nutriment digestibility in lactating cows, respectively. In the current study, a 3-times-lower dose of dietary butyric acid affected rumen papillae dimensions and rumen fermentation characteristics in growing bulls. Further studies are warranted to determine an optimal dose of dietary Nabutyrate for growing and lactating cattle. However, in estimating of the practical dose, the high cost of Nabutyrate should be also considered.

Although in our study microencapsulated Na-butyrate was used to slow down the butyric acid release in the rumen, it cannot be excluded that this form of butyric acid supplementation resulted in some amount of Na-butyrate passing to the lower gastrointestinal tract. As a result, Na-butyrate supplementation may affect not only the rumen, but also the lower gastrointestinal 


\begin{tabular}{|l|}
\hline 口Control \\
\hline
\end{tabular}
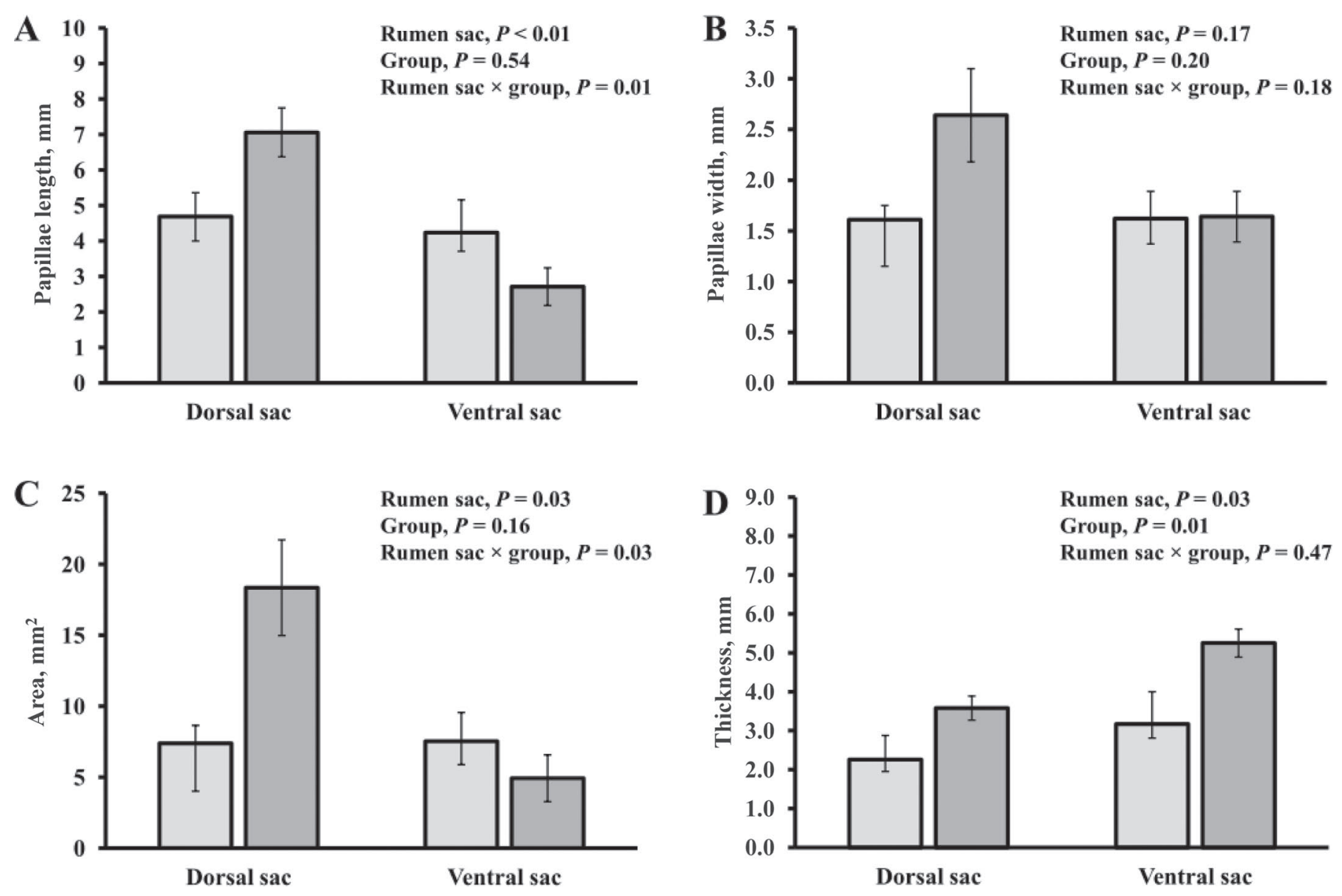

Figure 2. Least squares means and corresponding SE for papillae length (A), width (B) and cross-section area (C), and rumen muscle layer thickness (D) in trial 2. Each bar represents a mean for 5 and 6 observations for the control (no supplemental microencapsulated sodium butyrate) and Na-B (2\% of microencapsulated sodium butyrate in DM) groups, respectively.

tract structure and function, as suggested by other studies (Górka et al., 2011). In the study of Huhtanen et al. (1993), butyric acid infusion into the rumen had a positive effect not only on total-tract digestibility of $\mathrm{OM}$ and NDF, but also on digestibility of protein. This observation suggests a positive effect of butyric acid increase in the rumen also on postruminal digestion.

Dry matter intake before parturition is a very important factor affecting DMI postpartum and successful transition of cows to lactation (Grummer, 2007). However, because butyric acid is intensively metabolized to ketone bodies by the rumen epithelium (Bergman, 1990), its supplementation in the close-up period may increase plasma ketone bodies concentration and, consequently, the probability of ketosis in the first weeks postpartum. In our study, cows were fed $300 \mathrm{~g}$ of Na-butyrate/d, which resulted in intake of $71.1 \mathrm{~g}$ of butyric acid, and no negative effect on plasma BHBA was shown.

Altogether, the results of our study suggest that Na-butyrate supplementation in the close-up diet has potential to enhance rumen papillae growth and rumen adaptation to postpartum diet. However, lactation performance was not affected. Such preliminary results need to be confirmed on larger group of cows. In trial 2 , growing bulls were used, which did not necessarily reflect the effect of Na-butyrate on the rumen; also, papillae density was not measured, which do not allow determination of a true effect of Na-butyrate on nutrient absorption from the rumen. An optimal dose of Na-butyrate was also not verified in this study. As a result, further studies are warranted to determine the effect of Na-butyrate supplementation on performance of dairy cows. 


\section{ACKNOWLEDGMENTS}

This study was funded by Ministry of Science and Higher Education of Poland (Warsaw; DS-3217/ $\mathrm{KZZZiP/2012).}$

\section{REFERENCES}

AOAC International. 2007. Official Methods of Analysis. 18th ed. Rev. 2. AOAC Int., Gaithersburg, MD.

Aschenbach, J. R., G. B. Penner, F. Stumpff, and G. Gäbel. 2011. Ruminant nutrition symposium: Role of fermentation acid absorption in the regulation of ruminal pH. J. Anim. Sci. 89:1092-1107.

Bannink, A., J. France, S. Lopez, W. J. J. Gerrits, E. Kebreab, S. Tammingad, and J. Dijkstra. 2008. Modelling the implications of feeding strategy on rumen fermentation and functioning of the rumen wall. Anim. Feed Sci. Technol. 143:3-26.

Beever, D. E. 2006. The impact of controlled nutrition during the dry period on dairy cow health, fertility and performance. Anim. Reprod. Sci. 96:212-226.

Bergman, E. N. 1990. Energy contributions of volatile fatty acids from the gastrointestinal tract in various species. Physiol. Rev. 70:567-590.

DeFrain, J. M., A. R. Hippen, K. F. Kalscheur, and D. J. Schingoethe. 2006. Feeding lactose to increase ruminal butyrate and the metabolic status of transition dairy cows. J. Dairy Sci. 89:267-276.

Dengler, F., R. Rackwitz, F. Benesch, H. Pfannkuche, and G. Gäbel. 2014. Both butyrate incubation and hypoxia upregulate genes involved in the ruminal transport of SCFA and their metabolites. J. Anim. Physiol. Anim. Nutr. (Berl.) http://dx.doi.org/10.1111/ jpn.12201.

Dirksen, G., H. G. Liebich, G. Brosi, H. Hagemesiter, and E. Mayer. 1984. Morphologie der pansenschleimhaut und fettsaureresorption beim Rind-bedeutende faktoren fur gesundheit und Leistung. Zentralbl. Veterinarmed. A 31:414-430.

Duffield, T. F., D. Sandals, K. E. Leslie, K. Lissemore, B. W. McBride, J. H. Lumsden, P. Dick, and R. Bagg. 1998. Efficacy of monensin for the prevention of subclinical ketosis in lactating dairy cows. J. Dairy Sci. 81:2866-2873.

Edmonson, A. J., I. J. Lean, L. D. Weaver, T. Farver, and G. Webster. 1989. A body condition scoring chart for Holstein dairy-cows. J. Dairy Sci. 72:68-78.

Faisant, N., V. Planchot, F. Kozlowski, M. Pacouret, P. Colonna, and M. Champ. 1995. Resistant starch determination adopted to products containing high level of resistant starch. Sci. Alim. 15:83-89.

Goering, H., and P. Van Soest. 1970. Forage fibre analysis. USDA Ag. Handbook 379:1-20.

Górka, P., Z. M. Kowalski, P. Pietrzak, A. Kotunia, W. Jagusiak, J. J. Holst, R. Guilloteau, and R. Zabielski. 2011. Effect of method of delivery of sodium butyrate on rumen development in newborn calves. J. Dairy Sci. 94:5578-5588.

Grummer, R. R. 2007. Strategies to improve fertility of high yielding dairy farms: Management of the dry period. Theriogenology 68:S281-S288.

Grummer, R. R., M. C. Wiltbank, P. M. Fricke, R. D. Watters, and N. Silva-Del-Rio. 2010. Management of dry and transition cows to improve energy balance and reproduction. J. Reprod. Dev. 56(Suppl.):S22-S28.

Guilloteau, P., L. Martin, V. Eeckhaut, R. Ducatelle, R. Zabielski, and F. Van Immerseel. 2010. From the gut to the peripheral tissues: The multiple effects of butyrate. Nutr. Res. Rev. 23:366-384.
Huhtanen, P., H. Miettinen, and M. Ylinen. 1993. Effect of increasing ruminal butyrate on milk yield and blood constituents in dairy cows fed a grass silage-based diet. J. Dairy Sci. 76:1114-1124.

Ingvartsen, K. L. 2006. Feeding- and management-related diseases in the transition cow-Physiological adaptations around calving and strategies to reduce feeding-related diseases. Anim. Feed Sci. Technol. 126:175-213.

INRA. 2007. Alimentation des bovins, ovins et caprins. Besoins des animaux - valeurs des aliments. Tables INRA 2007. Editions Quae, France.

Kuzinski, J., and M. Rontgen. 2011. The mRNA and protein expression of ruminal MCT1 is increased by feeding a mixed hay/concentrate diet compared with hay ad libitum diet (Short Communication). Arch. Tierz. 54:280-286.

Laarman, A. H., A. L. Ruiz-Sanchez, T. Sugino, L. L. Guan, and M. Oba. 2012. Effects of feeding a calf starter on molecular adaptations in the ruminal epithelium and liver of Holstein dairy calves. J. Dairy Sci. 95:2585-2594.

Li, R. W., S. T. Wu, R. L. Baldwin, W. Z. Li, and C. J. Li. 2012. Perturbation dynamics of the rumen microbiota in response to exogenous butyrate. PLoS ONE 7:e29392 http://dx.doi.org/10.1371/ journal.pone.0029392.

Littell, R. C., P. R. Henry, and C. B. Ammerman. 1998. Statistical analysis of repeated measures data using SAS procedures. J. Anim. Sci. 76:1216-1231.

Loor, J. J., H. M. Dann, N. A. Janovick Guretzky, R. E. Everts, R. Oliveira, C. A. Green, N. B. Litherland, S. L. Rodriguez-Zas, H. A. Lewin, and J. K. Drackley. 2006. Plane of nutrition prepartum alters hepatic gene expression and function in dairy cows as assessed by longitudinal transcript and metabolic profiling. Physiol. Genomics 27:29-41.

Malhi, M., H. Gui, L. Yao, J. R. Aschenbach, G. Gabel, and Z. Shen. 2013. Increased papillae growth and enhanced short-chain fatty acid absroption in the rumen of goats are associated with transient increases in cyclin D1 expression after ruminal butyrate infusion. J. Dairy Sci. 96:7603-7616.

Mentschel, J., R. Leiser, C. Mülling, C. Pfarrer, and R. Claus. 2001. Butyric acid stimulates rumen mucosa development in the calf mainly by a reduction of apoptosis. Arch. Tierenahr. 55:85-102.

Penner, G. B., M. Taniguchi, L. L. Guan, K. A. Beauchemin, and M. Oba. 2009. Effect of dietary forage to concentrate ratio on volatile fatty acid absorption and the expression of genes related to volatile fatty acid absorption and metabolism in ruminal tissue. J. Dairy Sci. $92: 2767-2781$

Reynolds, C. K., B. Dürst, B. Lupoli, D. J. Humphries, and D. E. Beever. 2004. Visceral tissue mass and rumen volume in dairy cows during the transition from late gestation to early lactation. J. Dairy Sci. 87:961-971.

SAS. 2002. The SAS System Version 9.2, SAS Institute Inc., Cary, NC Shen, Z., S. Kuhla, R. Zitnan, H. M. Seyfert, F. Schneider, H. Hagemeister, A. Chudy, B. Löhrke, J. W. Blum, H. Hammon, and J. Voigt. 2005. Intraruminal infusion of n-butyric acid induces an increase of ruminal papillae size independent of IGF-1 system in castrated bulls. Arch. Anim. Nutr. 59:213-225.

Wiese, B. I., P. Górka, T. Mutsvangwa, E. Okine, and G. B. Penner 2013. Interrrelationship between butyrate and glucose supply on butyrate and glucose oxidation by ruminal epithelial preparations. J. Dairy Sci. 96:5914-5918. 